WM2008 Conference, February 24-28, 2008, Phoenix, AZ

\title{
K-1435 Wastewater Treatment System for the Toxic Substances Control Act Incinerator Wastewater at the East Tennessee Technology Park, Oak Ridge, TN* 8376
}

\author{
Christopher A. Beck, Senior Project Manager, Golder Associates Inc. \\ Dr. Erich W. Tiepel, Principal, Golder Associates Inc. \\ Mark D. Swientoniewski, P.E. Senior Project Engineer, Bechtel Jacobs Company LLC \\ Kevin R. Crow, P.E., Project Manager, CDM
}

\begin{abstract}
This paper will discuss the design and performance of a wastewater treatment system installed to support the operation of a hazardous waste incinerator. The Oak Ridge Toxic Substances Control Act Incinerator (TSCAI), located at the East Tennessee Technology Park (ETTP), is designed and permitted to treat Resource Conservation and Recovery Act (RCRA) wastes including characteristic and listed wastes and polychlorinated biphenyl (PCB)-contaminated mixed waste. The incinerator process generates acidic gases and particulates which consist of salts, metals, and radionuclides. These off-gases from the incinerator are treated with a wet off-gas scrubber system. The recirculated water is continuously purged (blow down), resulting in a wastewater to be treated. Additional water sources are also collected on the site for treatment, including storm water that infiltrates into diked areas and fire water from the incinerator's suppression system. To meet regulatory requirements for discharge, a wastewater treatment system (WWTS) was designed, constructed, and operated to treat these water sources.
\end{abstract}

The WWTS was designed to provide for periodic fluctuation of contaminant concentrations due to various feed streams to the incinerator. Blow down consists of total suspended solids (TSS) and total dissolved solids (TDS), encompassing metals, radionuclide contamination and trace organics. The system design flow rate range is 35 to 75 gallons per minute (gpm). The system is designed with redundancy to minimize time off-line and to reduce impacts to the TSCAI operations.

A novel treatment system uses several unit operations, including chemical feed systems, two-stage chemical reaction treatment, microfiltration, sludge storage and dewatering, neutralization, granular activated carbon, effluent neutralization, and a complete programmable logic controller (PLC) and human-machine interface (HMI) control system.

To meet the space requirements and to provide portability of the WWTS to other applications, the system was installed in three, over-the-road semi trailers, and interconnected with piping and power. Trailers were oriented on a small site footprint to facilitate ease of installation. A remote sump pump skid was provided to convey water from two holding sumps adjacent to the treatment process. An accumulation tank and pump were also provided to receive miscellaneous wastewaters for treatment if they meet the waste acceptance criteria.

The paper will include details of the technology used in the design, the requirements for compliance, and the initial performance demonstration and jar testing results. The WWTS successfully allowed for highly efficient, high-volume treatment with compliant discharge to off-site surface water.

\section{INTRODUCTION}

The TSCAI, located at the ETTP, is designed and permitted to treat RCRA wastes including characteristic and listed wastes and PCB-contaminated mixed waste. The incinerator process generates acidic gases and particulates which consist of salts, metals, and radionuclides. These off-gases from the incinerator are treated with a wet off-gas scrubber system to reduce the air pollutants to emissions levels

*Work performed under Subcontract 23900-BA-OR081F with Golder Associates Inc. under Bechtel Jacobs Company LLC; contract DE-AC0598 OR22700 with the U.S. Department of Energy. The submitted manuscript has been authored by a contractor of the U.S. Government under Contract DE-AC05-98OR22700. Accordingly, the U.S. government retains a nonexclusive, royalty-free jicense to publish or reproduce the

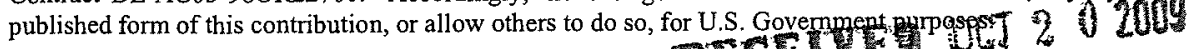


in compliance with the RCRA, Toxic Substances Control Act (TSCA), Clean Air Act (CAA), and National Emission Standards for Hazardous Air Pollutants (NESHAP) requirements. The recirculated water is continuously purged (blow down) resulting in a wastewater to be treated. The water is discharged to two 30,000-gallon purge sumps and then transferred to two 40,000-gallon surge sumps. A storage tank is planned for the system to provide additional surge capacity. Additional water sources are also collected on the site for treatment, including storm water that infiltrates into diked areas and fire water from the incinerator's suppression system. To meet the compliance for discharge, the WWTS was designed, constructed, and is presently being operated to treat these water sources.

\section{THE CHALLENGE}

Purged water generated at the TSCAI was being transferred from the surge sumps to an existing ETTP treatment facility, the Central Neutralization Facility (CNF), via an existing overhead pipeline for treatment. The treated effluent from the CNF was then transmitted through a 3.5-mile-long pipeline into the Clinch River at National Pollutant Discharge Elimination System (NDPES) Permit Outfall 001 (Clinch River Mile 12.0). CNF treated other streams in the past but the non-TSCAI liquid waste streams previously treated at the CNF have been eliminated, and the CNF will be shut down as part of an overall decontamination and decommissioning (D\&D) of the ETTP site. The planned shutdown, therefore, created the need for a separate WWTS for treating the TSCAI wastewaters and other miscellaneous wastewater. This new system had to be located within the TSCAI facility footprint for TSCAI to operate independently while the rest of the ETTP was undergoing D\&D. After treatment at the TSCAI WWTS, effluent will be pumped through the existing overhead transfer line, which connects to the existing discharge pipeline to Outfall 001. This effluent will be in compliance with the NPDES Permit and the Derived Concentration Guide (DCG) values for ingested water from U.S. Department of Energy (DOE) Order 5400.5

The influent for the new WWTS is chemically complicated and highly variable. Although historic records of liquid waste streams exist, the feed streams anticipated for the TSCAI are constantly changing in composition. Waste Acceptance Criteria were established for the treatment system based on historic information and a prediction of the anticipated new waste. The influent could not be defined at the time of the design because the feed streams to the TSCAI vary as the incinerator supports changed operations at Oak Ridge and other DOE sites. As the feed varies, so does the blow down water.

The blow down water from the incinerator scrubber is elevated in temperature, with temperatures as high as $175^{\circ} \mathrm{F}$. The resultant treated water must comply with the existing NPDES Permit issued by the State of Tennessee and DCG values mandated by the DOE.

Table 1 indicates the chemical composition of the TSCAI scrubber blow down that was used as the design basis for the WWTS. This influent design basis was developed based on the historic data, data from test burns by the incinerator and forecast of future waste streams based on future feeds to the incinerator. The TDS in historic samples ranged up to 60 parts per million (ppm) while the TSS averaged just below 3,400 ppm. Organics including PCBs, oil and grease, and radionuclides in small quantities were included in the design basis for removal. The $\mathrm{pH}$ of the water is basic, averaging 8.3 Standard Units (SU). 
WM2008 Conference, February 24-28, 2008, Phoenix, AZ

Table I. TSCAI Blow Down Composition - Design Basis




WM2008 Conference, February 24-28, 2008, Phoenix, AZ

\begin{tabular}{|c|c|c|c|c|c|c|}
\hline Stream Description & & Influent & $\begin{array}{l}\text { Dewatered } \\
\text { Sludge }\end{array}$ & $\begin{array}{l}\text { Treated } \\
\text { Water } \\
\text { Discharge }\end{array}$ & $\begin{array}{c}\text { Treated Water } \\
\text { Concentration ( } \mu \mathrm{g} / \mathrm{L})\end{array}$ & $\begin{array}{l}\text { NPDES } \\
\text { Permit Limit } \\
\text { (ug/L) }\end{array}$ \\
\hline Parameter & Units & & & & & \\
\hline Oil \& Grease ${ }^{c}$ & $\mathrm{ppb}$ & 7,000 & & 30,000 & $\leq 26,000$ & 26,000 \\
\hline Parameter & Units & & & & & \\
\hline TSS $^{\mathrm{C}}$ & $\mathrm{ppb}$ & $1,348,400$ & & 30,000 & $\leq 31,000$ & 31,000 \\
\hline Radionuclides $^{d}$ & SOF & & & $\leq 0.2^{\mathrm{d}}$ & $\leq 0.2^{\mathrm{d}}$ & $0.2^{\mathrm{d}}$ \\
\hline
\end{tabular}

a. Regulated metals less than permit requirements as shown below

b. Regulated organics less than permit requirements as shown below

c. Values for metals, oil \& grease and TSS for historical data are all included in the sludge line.

d. DOE Order 5400.5 discharge limits for radioactive constituent sum-of-the-fractions (SOF) is 1.0. The target value for an individual radionuclide is 0.2 or less. 
WM2008 Conference, February 24-28, 2008, Phoenix, AZ

\section{PROCESS APPROACH}

The broad variability of the scrubber blow down water that included TSS, organics and radionuclide contamination necessitated design of a treatment process which could remove all of the trace constituents. Figure 1 shows a block process flow diagram indicating each major unit operation and the function each serves.

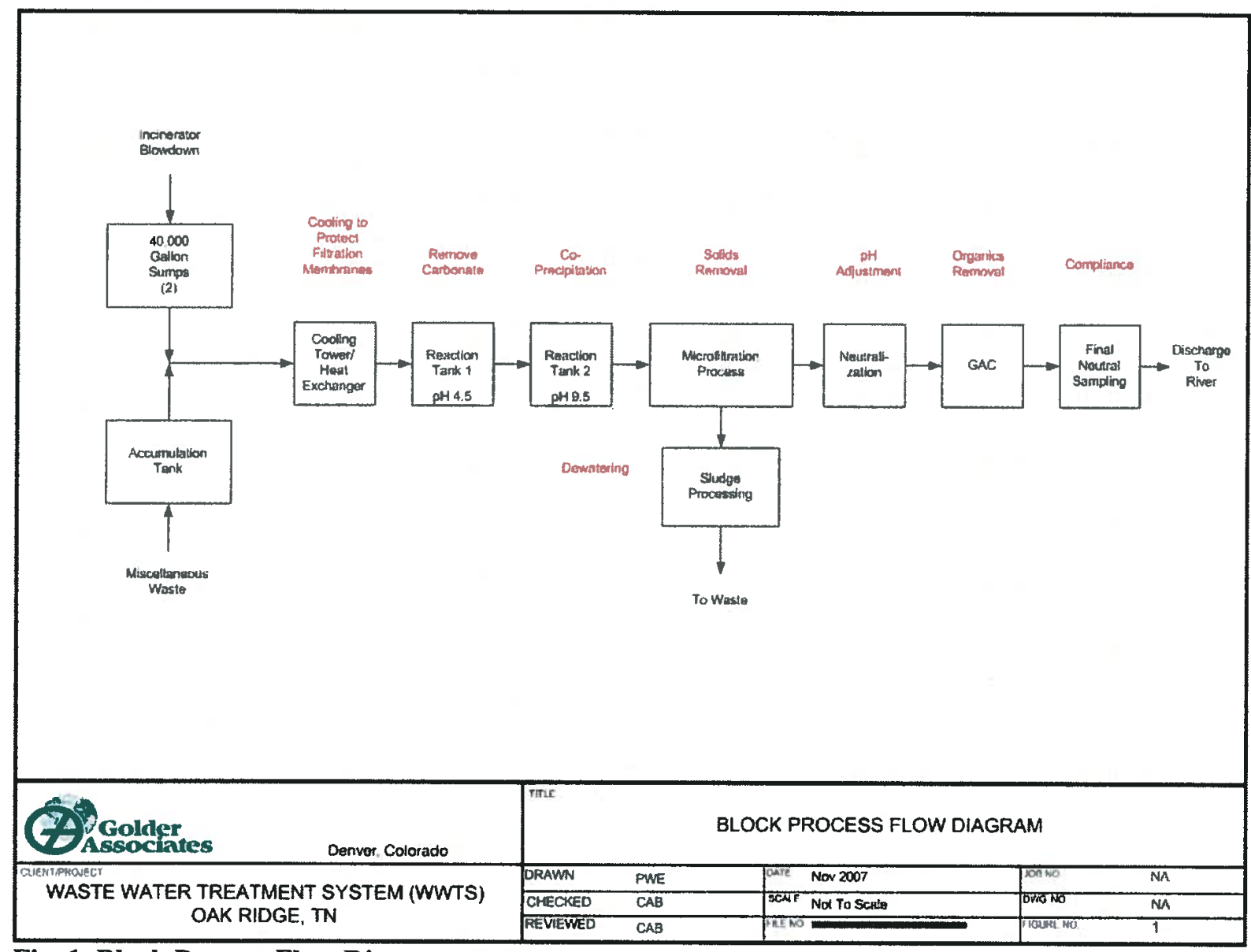

Fig. 1. Block Process Flow Diagram

A comprehensive treatment system was developed which used several traditional unit operations in a configuration that could successfully treat the contaminated blow down water. The unit operations included cooling, chemical feed systems, two-stage chemical reaction treatment, microfiltration, sludge storage and dewatering, neutralization, granular activated carbon (GAC), effluent neutralization and complete PLC and HMI control system.

\section{TECHNOLOGY}

\section{Cooling}

The initial step in the process is to reduce the temperature from $175^{\circ} \mathrm{F}$ to below $110^{\circ} \mathrm{F}$. This reduction is required to prevent damage to the membranes in the microfiltration unit, which are limited to a maximum incoming water temperature. A plate heat exchanger and evaporative cooling tower were used to bring incoming water to the system and cool it, with cooling tower water running countercurrent to the incoming water. With a 4-degree approach plate heat exchanger and the environmental conditions of ambient temperatures and wet bulb temperatures at the Oak Ridge site, an induced draft cross-flow 
WM2008 Conference, February 24-28, 2008, Phoenix, AZ

cooling tower could meet the cooling requirements for the system. Blow down water from the incinerator typically has some opportunity to cool because normal operations have the water stored in outdoor sumps for 8 to 16 hours before treatment.

\section{Two-Stage Reaction System}

A two-stage reaction system is used to remove alkalinity and precipitate dissolved metals. In the first stage, the $\mathrm{pH}$ is lowered to $4.5 \mathrm{SU}$ by addition of sulfuric acid $\left(\mathrm{H}_{2} \mathrm{SO}_{4}\right)$. The purpose of this step is to remove any alkalinity from the wastewater. $\mathrm{H}_{2} \mathrm{SO}_{4}$ was used instead of hydrochloric acid to prevent introduction of additional chlorides to the water (chloride is permit limited). Alkalinity will inhibit the precipitation and removal of radionuclides in the system. The process specifies a 15-minute reaction time, sufficient time for removal of alkalinity. Ferric chloride and calcium chloride solutions are also added in this stage for subsequent co-precipitation in stage two and as filtration aids for the microfiltration units.

The second stage raises the $\mathrm{pH}$ of the water to $9.5 \mathrm{SU}$ and provides a minimum of 15 minutes of reaction time for the co-precipitation process to occur. Caustic is used for the $\mathrm{pH}$ adjustment. In a traditional coprecipitation process, calcium hydroxide is added as a milk of lime. The use of lime was not desirable in this process, since un-reacted lime generates a greater sludge volume for disposal. Minimizing the sludge volume was an important consideration due to the costs involved with disposal of a radioactive, mixed waste sludge.

\section{Microfiltration}

The partially treated water gravity flows from the reaction tank system. The microfiltration system is used to remove the TSS, precipitated solids, and contaminants from the process stream to the microfiltration system's concentration tank. The microfiltration system incorporates proprietary crossflow tubular membranes which remove precipitated contaminants and produce a high quality filtrate suitable for discharge. Solids are accumulated in the tank and maintained at a concentration of $2-5 \%$ solids. The concentration tank is purged on a timed basis to maintain the concentrations in the tank. The membranes used in the microfiltration system are highly chemical resistant and, when needed, aggressive cleaning with oxidants or acids is possible. The design incorporates a separate membrane cleaning loop to allow for periodic membrane cleaning.

\section{Neutralization}

Water from the microfiltration unit flows into a neutralization tank. The $\mathrm{pH}$ is lowered using $\mathrm{H}_{2} \mathrm{SO}_{4}$ to meet the requirements of the NPDES Permit (6.0-9.0 SU).

\section{Organic Removal}

Treated water is pumped through two GAC columns which are configured for lead-lag processing to remove trace organics from the wastewater stream. Maximum flow through the units provides a loading of 6 gallons per minute per square foot of area.

\section{Trace Strontium/Cesium Removal}

An optional system to treat strontium/cesium with a zeolite ion exchange step was also designed. This option was not included in the final system provided, but could be added later very easily, if the waste water chemistry required it. 
WM2008 Conference, February 24-28, 2008, Phoenix, AZ

\section{Final Discharge}

After the GAC treatment, the treated water is checked for $\mathrm{pH}$ once more prior to discharge to the pipeline which discharges to the Clinch River. The final tank allows for the $\mathrm{pH}$ adjustment using either caustic or $\mathrm{H}_{2} \mathrm{SO}_{4}$.

\section{Sampling}

An automatic sampler collects a composite sample for NPDES compliance monitoring. Continuous inline monitors check conductivity, turbidity and $\mathrm{pH}$.

\section{Solid Waste Disposal}

Concentrated solids from the microfiltration concentration tank are pumped to a sludge holding tank. Solids are dewatered through a filter press. The filtrate is returned to the concentrate tank for further processing. Solids are typically dewatered to a 20 to $35 \%$ solids cake and loaded into drums for disposal.

\section{TREATMENT SYSTEM DESIGN BASIS}

The WWTS was designed to address periodic fluctuation of contaminant concentrations due to varying feed streams to the incinerator that result in a varying waste water quality. Blow down consists of suspended solids and TDS encompassing metals, salts, radionuclide contamination and trace organics.

The design basis for the flow ranged from $35-75 \mathrm{gpm}$. Current TSCAI operations indicated a need to operate at the higher flow rates. The flow range can vary to allow for brief system shutdowns for maintenance and large influxes of water associated with incinerator shutdown and fire suppression.

Reliability of the system was paramount since the WWTS is a key ancillary system for the incinerator operations. The design provided for redundancy of key components of the system to minimize down time associated with routine maintenance or equipment failure.

The WWTS design had to provide confidence that the system effluent would meet all requirements for compliance and discharge. The system also was required to provide the necessary instrumentation to monitor the discharge steam. As the D\&D operations continue at the ETTP, management of TSCAI wastewater will be critical. No "cushion" exists to store water if it fails to meet the permit requirements. The current WWTS was designed for continuous operations $24 / 7$.

\section{IMPLEMENTATION OF DESIGN}

To meet the space requirements and to provide portability of the WWTS to other potential applications at the ETTP, the system was installed in three, over-the-road semi trailers, and was interconnected with piping and power as shown in Figure 2. This installation required that the system have unique design requirements associated with the limited footprint. The system needed to be installed within the existing TSCAI complex, which encompasses office trailers, control rooms, and other ancillary facilities and equipment that support the incinerator operations.

The WWTS trailers were designed to occupy a small site footprint, facilitating their installation. 


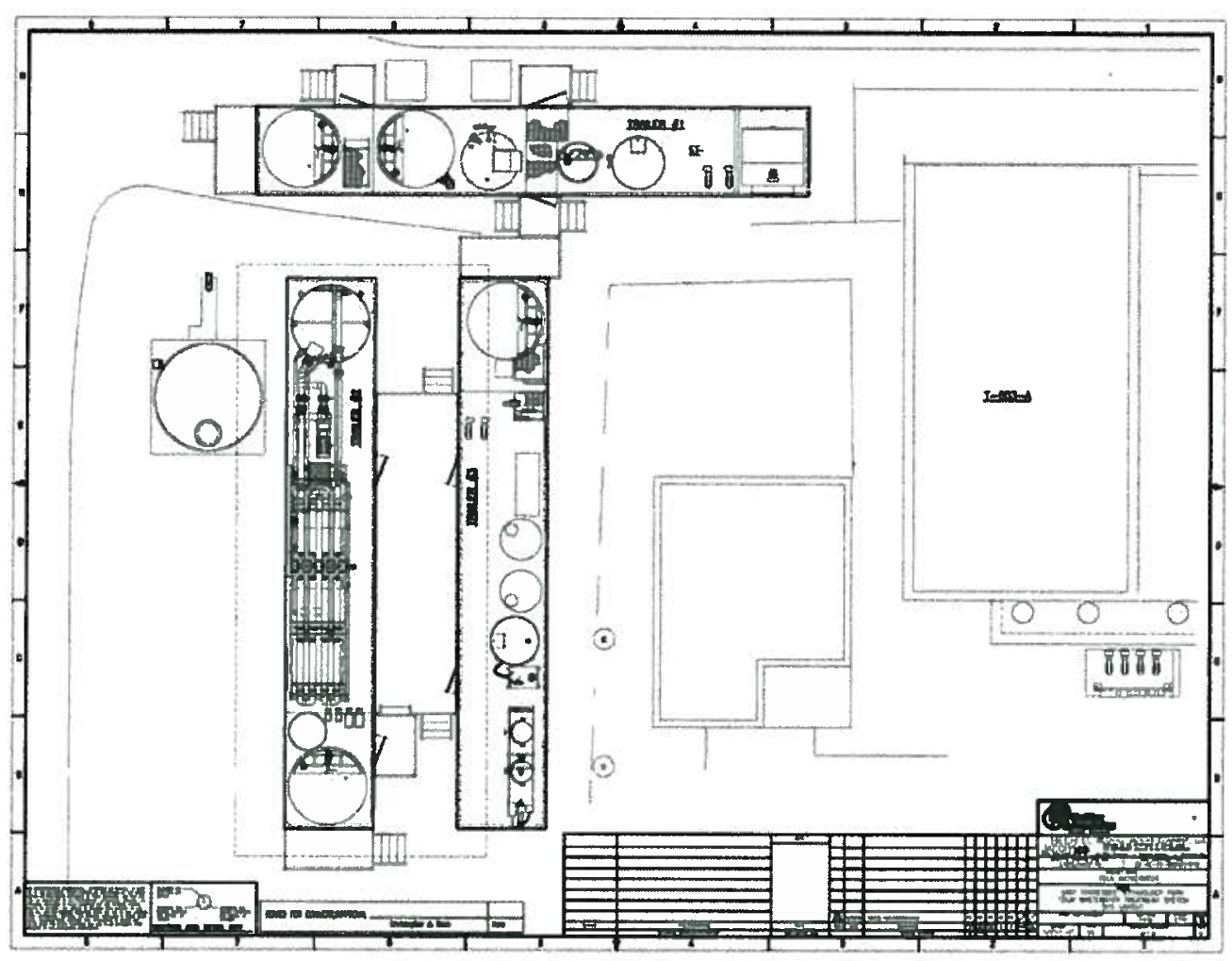

\section{Fig. 2. Site Layout}

The system piping and equipment needed to be freeze-protected and shielded from the elements. A trailer design provides this protection for the piping and equipment, eliminating the cost of insulating a complex system.

Trailer designs specified a single power feed to Trailer \#1 and distributed from that point to the other two trailers, eliminating the need for multiple power drops to support operations. Similarly, control and instrumentation wiring was centralized in one trailer and distributed as needed to the other trailers. Controls are available in one trailer or via Ethernet at the incinerator control room. The overall design of this trailer-mounted WWTS required minimal on-site construction.

The trailers also offered DOE the opportunity to reuse the system after the incinerator and it mission was fulfilled at the Oak Ridge site. Similar trailer-based water treatment systems were designed by Golder and Siemens (formerly RTG) and used by DOE at several Uranium Mill Tailings Remedial Action (UMTRA) sites.

\section{START-UP OPERATIONS}

Prior to full-scale operations, start-up assistance was provided by Golder and Siemens, the supplier of the microfiltration system. CDM completed bench-scale testing with a series of jar tests. The benchscale jar testing was performed on the same wastewater that was treated by the WWTS. The bench-scale jar tests were done to confirm that jar testing could be used as an operational aid to verify the impacts of chemical addition ratios and $\mathrm{pH}$ changes to the sludge production rates of the WWTS. The testing results were then used to optimize the $\mathrm{pH}$ set points and chemical dose rates for the reaction tanks.

System start-up and commissioning were used to verify operational procedures and train the operations personnel. Set points for operations were optimized. 
WM2008 Conference, February 24-28, 2008, Phoenix, AZ

\section{RESULTS}

Excellent effluent quality was produced by the WWTS. These results were reported to be superior to treatment previously being used on the site at the CNF.

The WWTS has successfully provided highly efficient, high-volume treatment with compliant discharge to off-site surface water. It is important to note that all of the heavy metal concentrations in the untreated influent wastewater used in system start-up were below the NPDES permit limits; however, the removal efficiencies for all of the heavy metals were still very high (>95\%). This information is presented graphically in Figure 3, Metals Concentration Comparison. A summary of the influent, process effluent, monthly permit limits and process removal efficiency is shown in Table II.

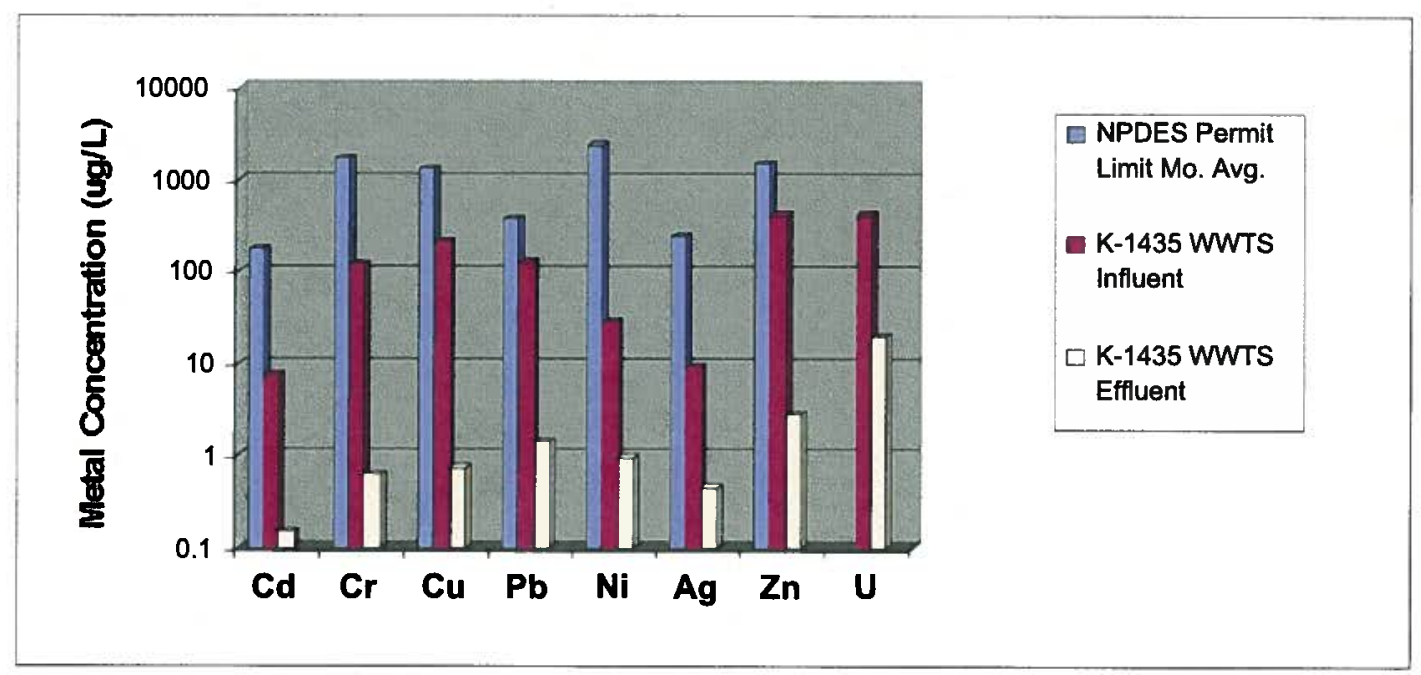

Fig. 3. Metals Concentration Comparision 
WM2008 Conference, February 24-28, 2008, Phoenix, AZ

Table II. Treatment Process Results

\begin{tabular}{|c|c|c|c|c|}
\hline Parameter & WWTS Influent & WWTS Effluent & Permitted Limit & \\
\hline $\mathrm{pH}$ & $6.8-7.4 \mathrm{SU}$ & $6.98-7.02 \mathrm{SU}$ & $6.0-9.0 \mathrm{SU}$ & \\
\hline Temperature & $121-107^{\circ} \mathrm{F}$ & $95-89{ }^{\circ} \mathrm{F}$ & NA & \\
\hline Constituents & $\begin{array}{l}\text { WwTS } \\
\text { Influent } \\
\text { (ug/L) }\end{array}$ & $\begin{array}{c}\text { WWTS Effluent } \\
(\mu g / L)\end{array}$ & $\begin{array}{l}\text { Permitted Limit } \\
(\mu g / L)\end{array}$ & $\begin{array}{l}\text { Removal } \\
\text { Efficiency\% }\end{array}$ \\
\hline Cadmium & $7.8-14$ & 0.15 & 180 & $>98.1-98.9$ \\
\hline Chromium & $111-122$ & $0.42-0.64$ & 1,710 & $99.4-99.5$ \\
\hline Copper & $185-213$ & $0.74-1.2$ & 1,340 & $99.4-99.7$ \\
\hline Lead & $125-126$ & $\leq 1.4$ & 380 & $>98.9$ \\
\hline Nickel & $28-29$ & 0.95 & 2,380 & $>96.6-96.7$ \\
\hline Silver & $9.3-16$ & $\leq \quad 0.45-0.65$ & 240 & $>95.2-95.9$ \\
\hline Zinc & $413-564$ & $2.2-2.8$ & 1,480 & $99.3-99.6$ \\
\hline Cyanide & 5 & 5 & 650 & NA \\
\hline Chloroform & 5 & $\leq$ & 500 & $\mathrm{NA}$ \\
\hline Carbon Tetrachloride & 5 & $\leq$ & 500 & NA \\
\hline Tetrachlorethylene & $\leq$ & $\leq$ & 700 & NA \\
\hline Trichloroethylene & $\leq$ & $\leq 5$ & 500 & NA \\
\hline Vinyl Chloride & $\leq$ & $\leq$ & 200 & NA \\
\hline Benzene & $\leq$ & $\leq$ & 5 & NA \\
\hline Ethylbenzene & $\leq$ & $\leq$ & 10 & NA \\
\hline Toluene & 2 & $\leq$ & 10 & $\mathrm{NA}$ \\
\hline PCBs & 0.2 & 0.2 & 0.22 & $\mathrm{NA}$ \\
\hline Oil \& Grease & 1,000 & $\leq \quad 1,000$ & 26,000 & NA \\
\hline TSS & $\leq \quad 5,000$ & $\leq \quad 5,000$ & 31,000 & NA \\
\hline \multicolumn{5}{|l|}{$\begin{array}{l}\text { Radionuclides } \\
\text { (Notes } \mathbf{a}, \mathrm{b} \text { ) }\end{array}$} \\
\hline Uranium & $410-680$ & $10-20$ & $\mathrm{NA}$ & $95.1-98.5$ \\
\hline SOF & $0.53-0.63$ & $0.025-0.028$ & 1.0 & NA \\
\hline \multicolumn{5}{|c|}{$\begin{array}{l}\text { Notes: } \\
\text { a. DOE Order } 5400.5 \text { discharge limits for radioactive constituent sum-of-the-fractions (SOF) is } 1.0 \text {. The target } \\
\text { value for an individual radionuclide is } 0.2 \text { or less. } \\
\text { b. The analyzed radionuclides for the SOF computation include Americium, Carbon, Cobalt, Cesium, Hydrogen, } \\
\text { lodine, Neptunium, Plutonium, Technetium, Thorium, and Uranium. }\end{array}$} \\
\hline
\end{tabular}


Isotopic uranium analyses by alpha spectroscopy were performed on influent and effluent samples from the WWTS and on jar test samples. The results of these analyses for samples collected on May 11, 2007 are shown in Figure 4. Removal efficiencies resulted in exceeding expectations for predicted performance for each radioactive isotope. Total uranium removal efficiencies were $95.1 \%$ for the WWTS and $>93.9 \%$ for the jar test.

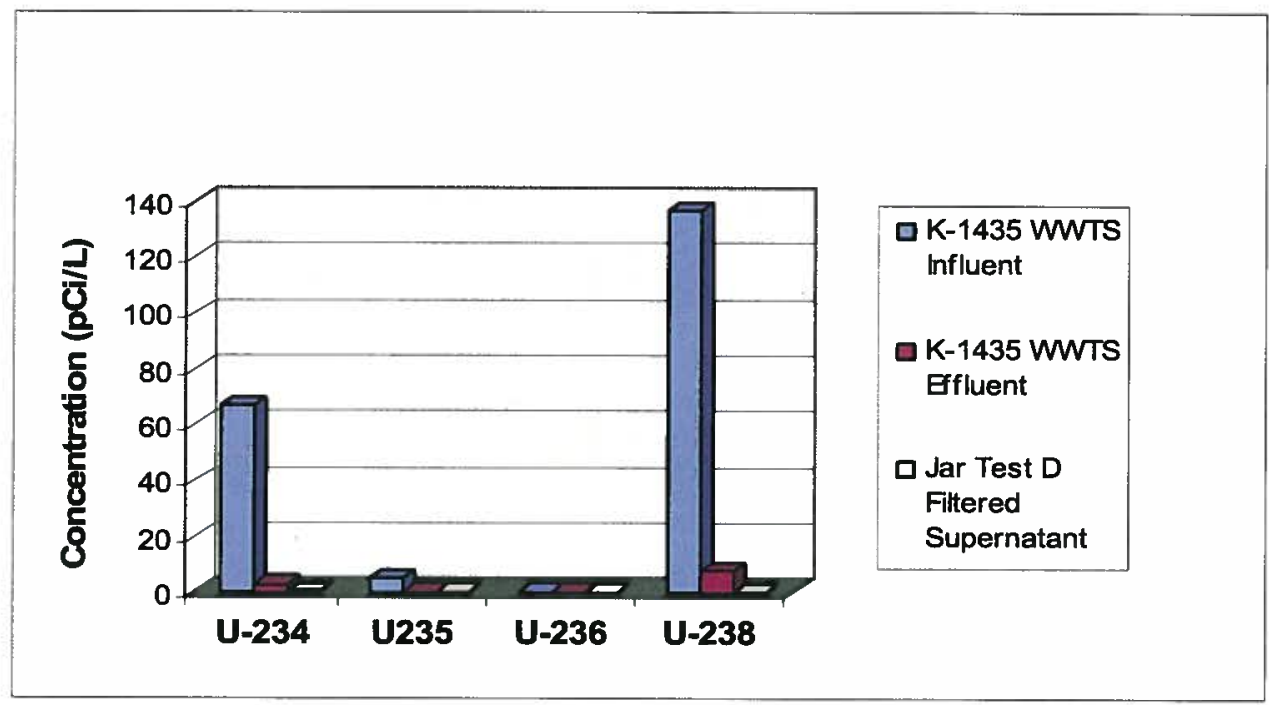

Fig. 4. Uranium Isotope concentrations in K-1435 WWTS Wastewater

Certain radionuclides other than uranium in the WWTS influent wastewater are of particular interest because their ingested water DCG screening values are relatively low. Three radionuclides with relatively low DCG values that were detected in the influent wastewater were Americium-241 (Am-241), Plutonium-239/240 (Pu-239/240), and Thorium-230 (Th-230). All three radionuclides were effectively removed below detection levels in both the WWTS and jar test as shown in Figure 5.

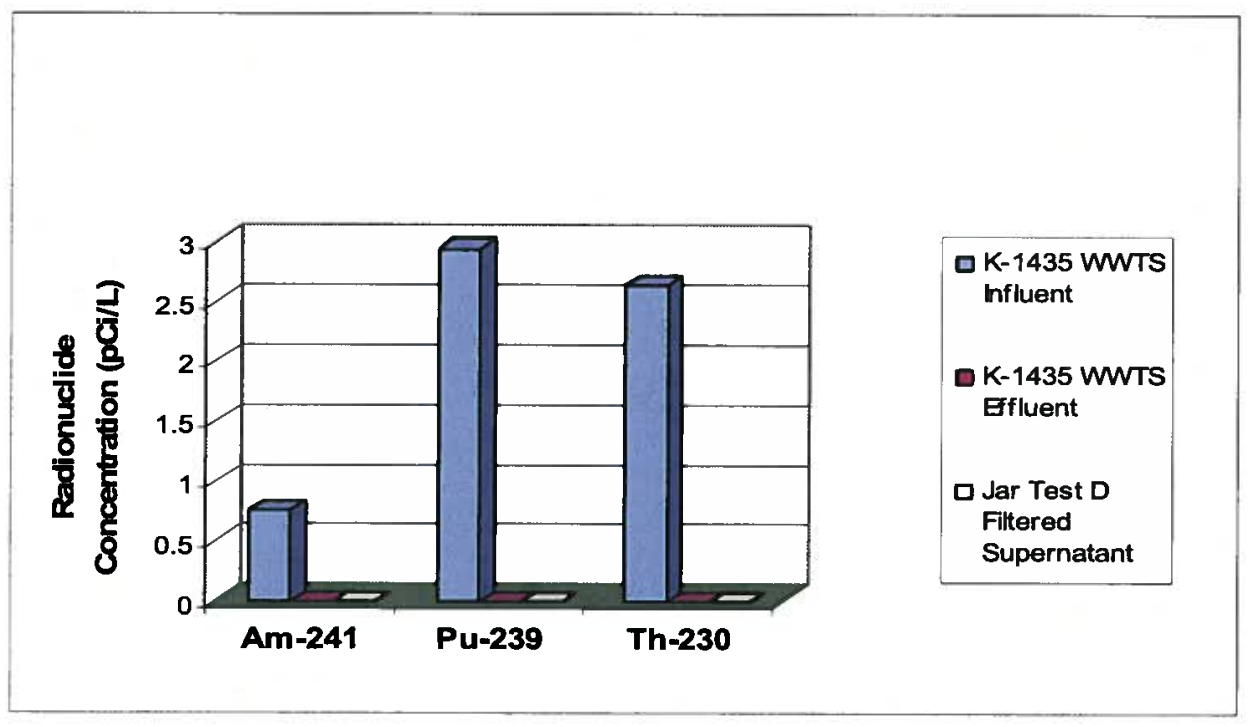

Fig. 5. Radionuclide Concentrations in K-1435 WWTS Wastewater 
The gross alpha and gross beta results show that, although alpha emitters in the wastewater tested are effectively removed by the WWTS and jar tests, some of the beta emitters in the wastewater are not effectively removed (Figure 6). In particular, tritium at an influent concentration of 3,670 picoCuries per liter $(\mathrm{pCi} / \mathrm{l})$ was not removed at all in the WWTS or jar test (Figure 7). This result is not unexpected as there is not a practicable method for removing tritium from liquid waste streams.

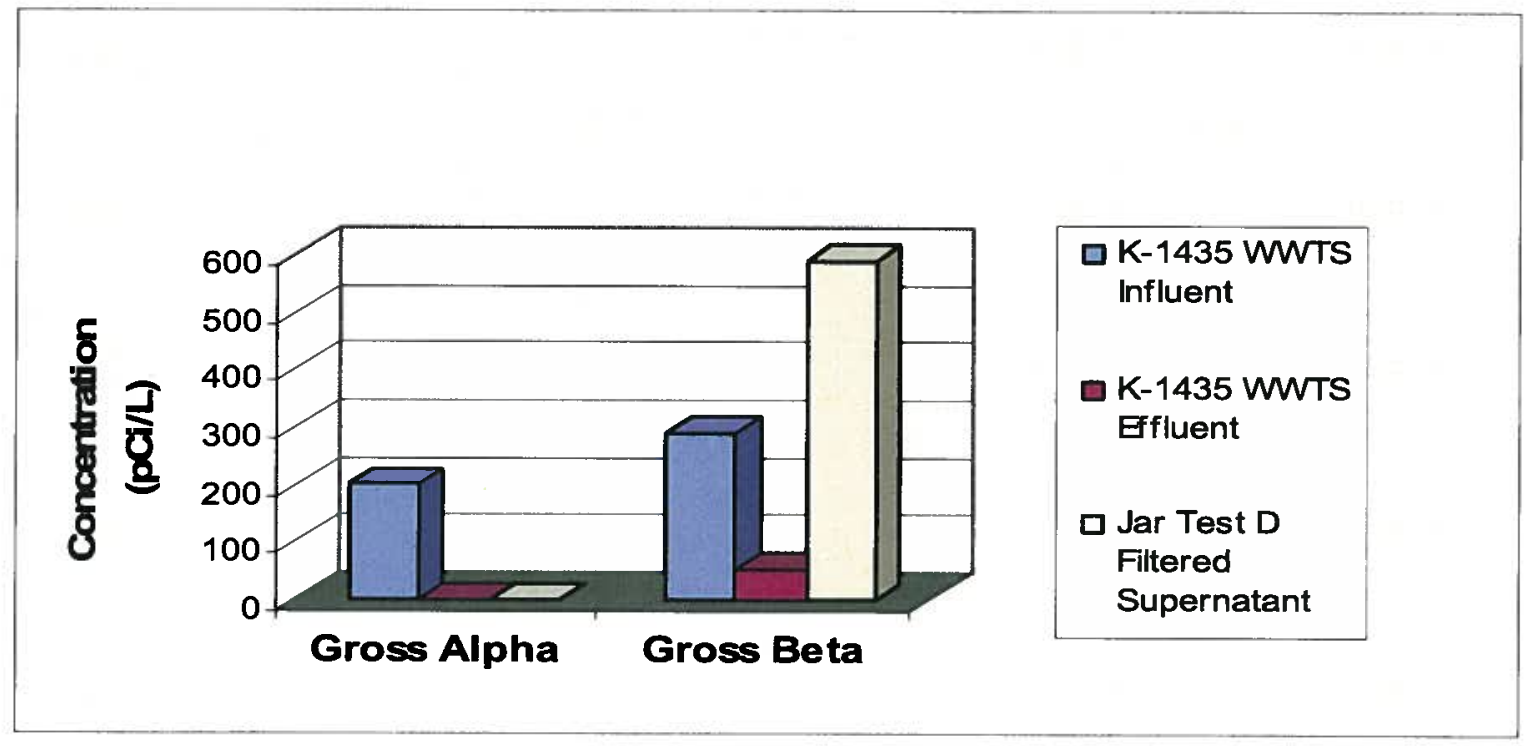

Fig. 6. Gross Alpha/Beta Concentrations in K-1435 WWTS Wastewater

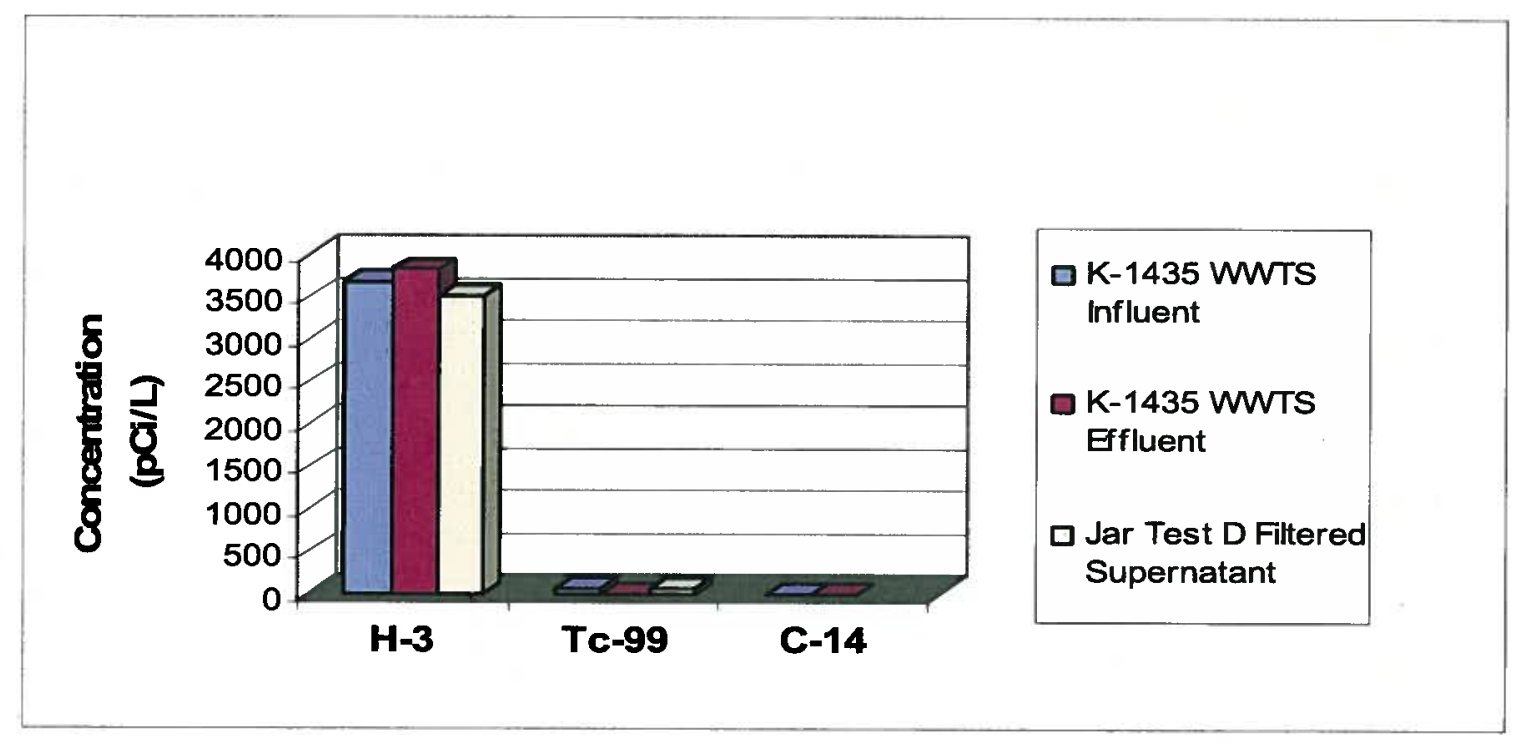

Fig. 7. Beta Emitter Concentrations in K-1435 WWTS Wastewater 
WM2008 Conference, February 24-28, 2008, Phoenix, AZ

\section{CONCLUSIONS}

The K-1435 WWTS provided very high heavy metal removal efficiencies ( 95 to $99.5 \%$ ) and excellent overall removal of the radionuclides from TSCAI blow down wastewater. The removal of radionuclides, as measured by the sum of the fractions of the DCGs for the WWTS effluent $(0.025$ and 0.028$)$, was nearly an order of magnitude below the operation/design target of 0.2 . Treatment in the WWTS resulted in approximately $95 \%$ reduction of radionuclides in terms of the sum of fractions of the DCGs.

There was good agreement between the jar test results and the performance of the WWTS. Jar testing proved to provide adequate guidance for the WWTS operators to adjust and optimize the various process variables.

The K-1435 WWTS design and operation fulfilled the requirements of the ETTP to have a reliable treatment system for TSCAI wastewater, capable of handling a varied feed stream, able to fit within the available footprint, and meeting the discharge requirements of the NPDES Permit and DOE Order 5400.5 . 